\title{
UMA ABORDAGEM DO DESIGN NO REAL E COMPLEXO MUNDO DO CONSUMO
}

\author{
Erika Simona dos Santos Ferreira \\ Universidade Federal de Pernambuco - UFPE \\ erikasimona@gmail.com \\ Kátia Medeiros de Araújo \\ Universidade Federal de Pernambuco - UFPE \\ katia_araujo@hotmail.com.br
}

\begin{abstract}
Resumo: Estimativas populacionais recentes sugerem uma grande mudança na configuração do mundo nas próximas décadas; marcadas por grande aumento populacional, tais mudanças prometem afetar intimamente todos os aspectos do desenvolvimento sustentável, trazendo consigo novos desafios e a potencialização de antigos problemas. Diante deste cenário, repensar os hábitos de consumo, as cidades, as comunicações e os serviços, torna-se cada vez mais urgente. E o design pode ter grande participação nisso. Partindo desse pressuposto, revisitamos o texto clássico do autor Victor Papanek ("Design for the real world", de 1971), contrapondo-o ao recente "Design para um mundo complexo", de Rafael Cardoso (2012), que busca dialogar com o texto anterior se propondo a enfrentar os dilemas colocados pela contemporaneidade. Desta maneira, discutimos o papel do design na sociedade sob a ótica das relações de consumo, desejo e necessidade, buscando entender o papel do designer no contexto da contemporaneidade, e a relevância e atualidade de questões propostas por Papanek - revistas por Cardoso, entre outros - ainda nos dias de hoje.
\end{abstract}

Palavras-chave: Design, consumo, sociedade, contemporaneidade.

\begin{abstract}
Populational estimatives presented nowadays point out great changes in the world configuration within the next decades; marked by large populational increase, such changes promise to deeply affect every aspect of sustainable development, bringing along new challenges and expanding old problems. The given scenario makes it increasingly urgent rethinking consumption habits, cities, communication and services; design actions can play a big role in this. Based on this assumption, the article reviews the classic text by Victor Papanek ("Design for the real world", 1971), interposing it to the recent "Design para um mundo complexo", by
\end{abstract}


Rafael Cardoso (2012). It aims to establish a dialog with the previous text, proponing new ways to deal with new dilemmas presented by conteporaneity. This way, the role of design within society is discussed from the viewpoint of consumption, needs and desire relations. We aim to understand the role of the designer on contemporaneity context, besides the relevance and actuality of the questions presented by Papanek, rediscussed by Cardoso (among many others), still nowadays.

Keywords: Design, consumption, society, contemporaneity.

\section{INTRODUÇÃO}

Tendências que indicam um aumento radical da expectativa de vida, aliadas à queda dos índices de natalidade, sugerem uma mudança na configuração do mundo nas próximas décadas. Nunca vivemos tanto. Nos últimos 50 anos, o número de habitantes do mundo mais que duplicou, passando de 2,5 bilhões em 1950 para 7 bilhões em 2011; estima-se que esse número chegue a 9,6 bilhões de pessoas, em 2050 (UNFPA, 2014). Também nos últimos 50 anos, tivemos a maior produção de artefatos (e resíduos) da história (CARDOSO, 2012).

Pelos cálculos da Organização das Nações Unidas (ONU, 2013), o ano de 2047 será um marco: pela primeira vez haverá um número maior de pessoas com mais de 60 anos do que com menos de 15 . Até 2050, o mundo terá mais de 3 bilhões de pessoas acima de 50 anos; a maioria delas -2 bilhões - viverá nos centros urbanos.

O aumento da longevidade tende a evidenciar uma série de desafios para a humanidade - a começar pelo tamanho da população. Para uma sociedade continuamente acostumada a cultuar a juventude, o fato de que o mundo terá cada vez mais pessoas de meia-idade e idosos pode representar a emergência de novos paradigmas sociais, bem como um gatilho para se repensar urgentemente velhos problemas.

Segundo relatos do Fundo de População das Nações Unidas, agência ligada à ONU, os fatores populacionais afetam intimamente todos os aspectos do desenvolvimento sustentável, incluindo pobreza, urbanização, envelhecimento, segurança do meio-ambiente, migração, questões de gênero e de saúde reprodutiva (UNFPA, 2014).

Diante deste cenário, repensar os hábitos de consumo, as cidades, as comunicações e os serviços, se torna cada vez mais urgente. E o design pode ter grande participação nisso.

Autores como Cardoso (2012) e Papanek (1971), por exemplo, ainda que separados por décadas em seus escritos, compartilham de uma visão sociocultural do design, ao encará-lo como uma ferramenta das mais poderosas que o homem possui para moldar seus produtos/artefatos, ambientes e, por extensão, a si mesmos; o design é encarado como um verdadeiro agente de mudança social. Como diria Cardoso (2012), "em um mundo cada vez mais complexo, os desafios do designer são cada vez mais profundos".

O designer no mundo contemporâneo tem suas defesas éticas e ideológicas constantemente postas à prova, sempre que os imperativos comerciais predominam sobre a produção (AMORIM, 2012). A excessiva manutenção da demanda e do 
aumento das vendas através do redesign de objetos, por exemplo, instigada principalmente pela criação de desejos e não de necessidades, continua sendo um dos grandes dilemas da profissão, assim como o envolvimento na fabricação de produtos cujo único objetivo é a adequação em algum tipo de mercado. Como diria Papanek (1971), "produtos inúteis". Ainda na década de 70, o autor já colocava que "o projeto de um único produto não relacionado a seu ambiente sociológico, psicológico e arquitetônico da cidade já não é possível nem desejável".

\section{POR QUE DESIGN? O MUNDO REAL E O MUNDO COMPLEXO}

O paradigma de design dominante na nossa sociedade tem sido o de projetar para o mercado: artefatos produzidos por um fabricante e dirigidos a um consumidor; caminhos alternativos têm recebido pouca atenção. O campo de abrangência do design, no entanto, trata-se de um domínio extremamente dinâmico, interdisciplinar, fortemente influenciado pela economia, tecnologia e cultura (AMORIM, 2007).

Essa abertura conceitual e disciplinar é celebrada e estimulada pelos que encaram o design como manifestação possível "em qualquer área do conhecimento e práxis humana" (AMORIM, 2007). Papanek (1971), por exemplo, foi um dos pioneiros na defesa dessa ideia, ao sentenciar que "todos os homens são designers". Segundo ele, design é um esforço inconsciente para impor ordem significativa às coisas, devendo ser, também, significativo. As colaborações de Papanek para o design, no entanto, não se esgotam nas definições.

Entre os pensamentos críticos sobre design, produção e consumo que adquiriram relevo em décadas passadas e ainda se fazem presentes, podemos destacar o discurso por um design ambiental e socialmente comprometido defendido por Victor Papanek, nos anos 70. No clássico "Design for the real world" (1971) ("Design para o mundo real", na tradução para o português), o autor cita a atuação do design em favor do desenvolvimento sustentável, sendo que seu texto encontra ressonância até os dias de hoje.

Em seu livro, Papanek já alertava para a perda de sentido do design de perfil modernista então crescente, e convocava os designers a saírem de seus universos autorreferentes para projetarem soluções para o "mundo real". Coloca os designers socialmente responsáveis em conflito com um mercado comercial que prospera com a criação excessiva de produtos ditos "inúteis", conforme sua definição.

Com o intuito de fazer uma crítica ao baixo envolvimento de designers na solução de problemas declarados como sérios, pelo autor - considerando seu planejamento futuro em termos sociais e ecológicos -, logo no início do texto sentencia que "existem profissões mais danosas que o design, porém são poucas" (PAPANEK, 1971). Complementa com a afirmação de que o desenho industrial inventa "idiotices, que são anunciadas pelos publicitários", criticando a alta preocupação dos projetistas apenas com o estilo e "promoções encantadoras" (PAPANEK, 1971).

Com essa postura extrema, o autor ressalta que as responsabilidades sociais e morais do designer deveriam envolver necessidades básicas da humanidade. Alerta também que, ao fazerem um produto novo, os designers podem estar gerando um novo problema ao invés de solucionar uma necessidade - através de projetos que não atendem às verdadeiras demandas do público real, mas a interesses alheios a eles. 
Por outro lado, ao criticar asperamente a economia de mercado, Papanek parece limitar as opções para um designer social (MARGOLIN, 2004). Ele defende que designers socialmente responsáveis devem agir fora das tendências de mercado, mas orienta bem pouco o leitor de como isso poderia ser feito. Parece, assim, que seu argumento se mostra mais forte criticando o status estabelecido do que proporcionando alternativas.

Entre os problemas do mundo real, Papanek já colocava, na década de 70, questões como a gestão da água e do lixo, a mobilidade urbana, o aquecimento global, a poluição do ar, as indústrias do alumínio e agrícola e o consumo irresponsável, entre outras. Problemas esses que se tornaram ainda mais profundos, 40 anos depois.

Devido à atualidade das questões propostas por Papanek, Cardoso, em seu "Design para um mundo complexo" (2012), busca dialogar com a discussão levantada pelo autor, se propondo a enfrentar os dilemas colocados pela contemporaneidade e atualizando a discussão em torno do papel do design na sociedade. Ele retoma a mudança de perspectiva dos valores modernistas, revendo noções básicas como forma, função e significado.

Cardoso (2012) procurou aprofundar o ataque à noção modernista de função, atualizando o mundo real de então, "cuja materialidade passou definitivamente a ser envolvida e permeada por uma camada de informação e imaterialidade". Ao revisitar o tema, o autor propõe-se a um debate envolvendo questões de interesse social como a tônica para a discussão sobre design; durante este percurso, no entanto, Cardoso se atém aos limites do simbólico, não lançando proposições, ou ainda, propondo argumentos de maneira evasiva. Ao divagar por várias ideologias atualmente vigentes no campo do design, não relaciona, porém, as colocações objetivamente.

Em relação à abordagem da sustentabilidade, por exemplo, o autor levanta a questão do que o design pode colaborar neste sentido, mas o faz de maneira superficial. Limita-se a questão da ecologia à "reciclagem" (pela ressignificação dos artefatos), além de tornar confusas as responsabilidades envolvidas: tudo depende de símbolos, e não de ações e de pessoas concretas. $\mathrm{O}$ autor aparentemente limita a responsabilidade social do designer ao estudo do ciclo de vida dos artefatos (significação após descarte). Não questiona, por exemplo, as relações de consumo. Pergunta-se "Como projetar qualquer coisa para sobreviver além do seu uso previsto?" (CARDOSO, 2012), mas não se coloca sobre o fato de "projetar qualquer coisa".

Numa realidade na qual a inovação tecnológica ironicamente acelera a obsolescência (artificial ou estilística), e tem sido usada para criá-la de maneira programada, estimulando a constante aquisição e/ou reposição de produtos lançados na última moda, chegamos a um ponto onde a questão ambiental também é uma preocupação mais do que nunca urgente.

Segundo o próprio Cardoso (2012), a produção voltada ao consumo incessante gera quantidades de lixo e resíduos praticamente impossíveis de administrar, como exemplo de um dos vários problemas que acometem nesse campo. Dessa maneira, é necessário não apenas discutir a ressignificação dos artefatos, mas discutir-se amplificadamente o impacto sociocultural que o design pode estabelecer nesse campo: suas relações com o consumidor/usuário, o produto e o cliente ou fabricante. 


\subsection{Design e consumo}

O consumo configura-se, no mundo atual, como o principal meio para a satisfação das necessidades humanas; e o design atua de forma determinante nesse processo.

Frequentemente associado ao uso - um dos mais importantes segmentos dentro do núcleo de competências do design -, o papel do usuário acaba restringindo a definição de design às considerações relativas a esse uso. Amorim (2007), no entanto, colabora com esta definição ao acrescentar o termo "consumidor" à associação relativa ao design, justificando que o usuário está ancorado a essa tipologia. Kotler (apud AMORIM, 2007), por exemplo, faz a seguinte distinção entre os papéis do consumidor:

- iniciador: sugere uma idéia de compra;

- influenciador: indivíduo cujo ponto de vista influencia na decisão de compra;

- decisor: decide sobre o processo da compra (o que, como, onde comprar);

- comprador: quem de fato realiza a compra;

- usuário: quem faz uso do produto.

Essa contribuição, portanto, reconhece o design em plena conexão não só com o uso, mas com o consumo em sua totalidade, inserido no contexto capitalista contemporâneo de produção (AMORIM, 2007).

Entende-se, desse modo, que muito mais do que mediar produção e uso, o design faz a interface entre produção e consumo, acrescentando complexidades de ordem econômica, social e cultural que não podem deixar de ser consideradas. Dentre estas complexidades, temos dois conceitos envolvidos no consumo que não podem deixar de ser abordados: necessidades e desejos.

Em relação às necessidades, Samara \& Morsch (apud AMORIM, 2007) as definem como situações de privação que, ao atingirem determinado nível, mobilizam o comportamento na busca de satisfação.

A hierarquização dessas necessidades, teorizada pelo psicólogo Abraham Maslow (apud AMORIM [7]), são estruturadas em escala piramidal, obedecendo a uma sequência de satisfação que parte da base para o topo, na seguinte ordem:

- fisiológicas: ligadas à manutenção da vida humana;

- de segurança: relativas à proteção do corpo, à busca de ordem, estabilidade e controle sobre a vida e o ambiente;

- sociais (de amor e de participação): vinculadas à afeição, integração e pertencimento;

- de auto-realização: remetem à realização pessoal em todo o seu potencial, onde o indivíduo explora ao máximo suas capacidades.

Os desejos, por sua vez, são a inscrição cultural e pessoal das necessidades humanas. São compartilhados por um grupo social, tendo como base as influências socioculturais e psicológicas desse meio. Assim, os desejos atuam na canalização e personalização das escolhas dos consumidores. No marketing, são explorados em função das características do produto que se quer vender (AMORIM, 2007). 
Em contrapartida a essas infinitas demandas - sejam elas necessidades ou desejos - estão os produtos, mediados pelo design de funções capazes de satisfazê-las.

Tais funções foram sistematizadas por alguns autores, como Löbach (2001), que divide as funções do produto em práticas, estéticas e simbólicas (atendem a carências de ordem social e psicológica). Segundo Amorim (2007), autores como Murakosky (que estabelece funções indicativas, formal-estéticas e simbólicas) Norman (dimensões visceral, comportamental e reflexiva do sistema emocional e cognitivo humano) fazem definições semelhantes.

Podemos considerar que, tanto para as necessidades quanto para os desejos existem respostas de design configuradas em forma de produtos: algumas voltadas a expectativas mais básicas, outras assentadas em ausências psicológicas e socioculturais (AMORIM, 2007). Neste último caso, vemos emergir o consumo simbólico, que denomina a relação que o consumidor estabelece com o produto no sentido de expressar sua identidade e se auto-afirmar.

Corroborando com esta linha de raciocínio, Daniel Miller (2009), ao falar sobre o consumo, entende a compra de produtos como um processo de criação de identidade, uma forma de criar cultura autêntica.

Em seu "Consumption and its consequences" ("Consumo e suas consequências"), o autor enfatiza o consumo como um ato de trabalho, atividade social na qual construímos nossa identidade cultural, mudamos e desenvolvemos nossas relações sociais. Fornece uma análise acerca do consumo contemporâneo a partir de suas próprias respostas etnográficas a este fenômeno, diferindo drasticamente de visões convencionais e aceitas para pensar o consumo (como materialista e individualista, exclusivamente).

Miller (2009) ressalva ainda não devemos dissociar esse processo de uma reflexão sobre o que consumimos, visto que o consumo doméstico não pode ser dissociado de suas consequências em um panorama global (apesar da tendência em diluirmos as nossas responsabilidades em nossas relações de consumo). Segundo o autor, o modelo de economia de grande escala nos afasta do senso de responsabilidade, de maneira que as mesmas pessoas, enquanto trabalhadoras, podem ser atingidas pelas consequências de suas ações como consumidoras.

Sob a perspectiva de uma sociedade industrial, existe a tendência a construir o sentido do artefato a partir de sua fabricação (origem), distribuição (mercado e comércio) e consumo (compra e uso).

Segundo Cardoso (2012), vários outros fatores (relativos à situação material do objeto e à percepção que se faz dele) condicionam o significado do artefato, incidindo uns sobre os outros de modo complexo. A apreensão destes fatores deriva da relação entre usuários e artefatos, numa troca de informações e atribuições que se processa de modo contínuo. Ao mesmo tempo em que imbuímos um produto de significados, o produto colabora com a nossa construção, dinamicamente.

É importante ter em mente, contudo, que necessidades e desejos mesclam-se uns aos outros, assim como funções entrecruzam-se nos objetos; o que faz com que cada situação de consumo carregue uma lógica bastante particular desses elementos (AMORIM, 2007). 


\subsection{A indústria e o mercado}

Essa dinâmica em torno da satisfação de necessidades e desejos dos indivíduos, mediada pelo design e pelo consumo, conta, evidentemente, com a interferência da indústria, que é, de modo geral, responsável pelo diagnóstico (ou estabelecimento) das carências e das oportunidades existentes no mercado consumidor em que atuam.

Essa cooperação entre design e marketing no nível produtivo prevalece, em maior ou menor nível, com a atuação do designer ligada ao avanço e à inovação dos objetos industrializados, focando as necessidades e os desejos do consumidor es interesses de quem o contrata.

A contrapartida financeira, portanto, é o que tende a sinalizar as necessidades e desejos que serão contemplados, estimulados ou mesmo criados, e as soluções de design que de fato serão executadas. No panorama global do consumo, temos grandes instituições internacionais que existem como modelos, que se justificam baseadas em determinantes de demanda embasados em seus modelos de consumidores (e não nas necessidades reais de públicos específicos).

Miller (2009) aborda esta questão em relação a como o Estado e o comércio buscam universalizar o consumo, com vistas a potencializar o lucro. Segundo o autor, nesses modelos, o consumo se dá como continuação de forças capitalistas e burocracia, destruindo a diversidade local em nome da homogeneidade, ou incentivando uma diversidade que vende produtos sem real profundidade ou contribuição para o desenvolvimento cultural.

Sob um modelo de desenvolvimento de produtos para fabricação em massa, com objetivo de alcançar formas "universais" com boa aceitação a fim de obter grandes margens de lucro, Papanek (1971) critica o baixo nível de planejamento e o design sem responsabilidade social, no "design das massas". Para ele, a projetação de artefatos deveria considerar a natureza, a sociedade e o viés tecnológico, fatores inerentes à cultura e ao modo de vida dos grupos sociais.

\section{CONCLUSÃO}

Percebemos que o design e seu emprego têm, de fato, sido objetos de crítica, reflexão e renovação constante, ressoando também os conflitos e jogos de poder que marcam as sociedades em que ele se faz presente (AMORIM, 2007).

Nessa fogueira de interesses do mercado, o consumidor de baixa renda e suas demandas tendem a ficar, então, à margem dos projetos de design desenvolvidos com grandes verbas e sob os melhores cuidados da indústria, restando-Ihe, iniciativas isoladas de alguns empreendedores. Tal exemplo colabora na ilustração de que o designer poderia atuar, portanto, tanto na reprodução das desigualdades sociais e econômicas entre indivíduos e grupos sociais, quanto na atenuação dessas diferenças, dado seu papel no processo de desenvolvimento de artefatos.

Dessa maneira, ilustramos que a atividade do design, no contemporâneo, não se restringe apenas à produção de cunho persuasivo e comercial, mas pode exercitar também sua vocação para promover uma vida melhor para todos. Ações com foco na geração de trabalho e renda e na promoção da inclusão social caracterizam uma forma de prática sociocultural e politicamente engajada do design (BONSIEPE, 1999).

O designer, profissional focado na resolução de problemas e na sensibilidade para percebê-los, tem muito a colaborar nesse sentido. Ao beber na fonte da interdisciplinaridade, familiarizando-se com outros domínios, inserindo outras ciências 
no processo de design, é capaz de potencializar, assim, a habilidade de reconhecer, isolar, definir e resolver problemas.

O próprio Victor Papanek, no prefácio da segunda edição de seu controverso livro, considera que seu relato original sobre a contribuição que os designers ocidentais poderiam fazer para os países em desenvolvimento tinha sido "condescendente", subestimando o quanto eles poderiam aprender ali. Segundo Margolin (2004), a visão corrigida de Papanek sobre o potencial do design para as economias em desenvolvimento é hoje amplamente aceita.

Desde então, outros têm respondido ao chamado e procurado desenvolver programas de design para necessidades sociais, estendendo-se desde as necessidades de países em desenvolvimento até as necessidades sociais de idosos, pessoas em vulnerabilidade econômica, portadores de deficiências.

Sempre nos deparando com novas fronteiras, o design tende se afastar da materialidade e caminhar em direção à experiência, ao uso e à emoção. Cada vez mais os objetos de design serão imateriais, e o designer terá de aprender a projetar interações. É uma experiência de uso, de troca de informação (CARDOSO, 2012). O designer tem que ter a compreensão da necessidade do homem em termos globais, das ferramentas, processos e materiais que serão a base do designer amanhã (PAPANEK, 1971). Hoje e sempre.

\section{REFERÊNCIAS}

O AMORIM, Patrícia. Design, produção e consumo: uma exploração no contemporâneo. In: DISEÑO EN PALERMO. ENCUENTRO LATINOAMERICANO DE DISEÑO. 2007. Anais. Buenos Aires, Universidad de Palermo, 2007. ISSN: 1850-2032.

BONSIEPE, Gui. Design: do material ao digital. Florianópolis: FIESC/IEL, 1999.

CARDOSO, Rafael. Design para um mundo complexo. São Paulo: Cosac Naify, 2012.

FUNDO de população das Nações Unidas - UNFPA Brasil. População. Disponível em <http://www.unfpa.org.br/novo/index.php/populacao>. Acesso em: 24 fev. 2014.

LÖBACH, Bernd. Design industrial: bases para a configuração dos produtos industriais. SãoPaulo: Edgar Blücher. 2001

MARGOLIN, Victor; MARGOLIN, Sylvia. Um "Modelo Social de Design": questões de prática e pesquisa. Revista Design em Foco, Salvador, v.1, n.1, p. 43-48, julho/dezembro. 2004.

MILLER, Daniel. Consumption and Its Consequences. London: Polity Press, 2012.

ORGANIZAÇÃO DAS NAÇÕES UNIDAS - ONU. Perspectivas da População Mundial. 2013. Disponível em: <http://www.unfpa.org.br/Arquivos/SP-SWOP2013.pdf>. Acesso em: 23 fev. 2014. 
PAPANEK, Victor. Design for the real world: human ecology and social change. New York: Pantheon Book, 1971.

STOLARSKI, André. Os complexos desafios do designer contemporâneo. In: RESENHAS ONLINE. Disponível em:

<http://www.vitruvius.com.br/revistas/read/resenhasonline/11.124/4277>. Acesso em: 23 fev. 2014. 